\title{
Clinical utility gene card for: Aarskog-Scott Syndrome (faciogenital dysplasia) - update 2015
}

\author{
Alfredo Orrico ${ }^{\star, 1,2}$, Lucia Galli ${ }^{1}$, Jill Clayton-Smith ${ }^{3}$ and Jean-Pierre Fryns ${ }^{4}$ \\ European Journal of Human Genetics (2015) 23, doi:10.1038/ejhg.2014.178; published online 17 September 2014
}

Update to: European Journal of Human Genetics (2011) 19, doi:10.1038/ejhg.2011.108; published online 8 June 2011

\section{DISEASE CHARACTERISTICS}

1.1 Name of the disease (synonyms)

Aarskog-Scott Syndrome (AAS), faciodigitogenital syndrome, FGDY,

faciogenital dysplasia.

\subsection{OMIM\# of the disease}

305400 .

1.3 Name of the analysed genes or DNA/chromosome segments FGD1.

Variation locations are based on the following accessions:

NCBI Reference Sequence: NC_000023.11, NG_008054.1, NM_004463.2, NP_004454.2.

UniProtKB/Swiss-Prot: FGD1_HUMAN, P98174.

Ensamble: FGD1 Gene ENSG00000102302. Transcript FGD1-001 ENST00000375135.

Exons are numbered from 1 to 18 , starting at the translation initiation site, according to the previously published gene structure. ${ }^{1}$

\subsection{OMIM\# of the gene(s)}

300546.

\subsection{Spectrum of sequence variants}

Missense, nonsense, deletions and insertions are reported in addition to gross rearrangements. No variant hotspots or common variants are seen with the majority of variants being unique within families. Lists of disease-causing variants can be found at www.lovd. nl/FGD1 (Leiden Open Variation Database) and www.hgmd.cf.ac. uk/ac/index.php (Human Genoma database at the Institute of Medical Genetics in Cardiff). To the best of our knowledge, incorporating information from published articles, unpublished data and congress reports, 61 variants have been characterized. These comprise 32 missense variants, 16 frameshift variants, 6 nonsense variants, 4 splice site variants, 1 in-frame deletion and 2 gross deletions. ${ }^{2-10}$ In addition, a large duplication (exon 2-12) and a branch-point variant, both leading to a premature stop codon, have been described in affected families. ${ }^{11,12}$ Germline mosaicism has been reported. ${ }^{6}$ No definite genotype-phenotype correlation is apparent from comparison of patients with different variants; ${ }^{2,10}$ however, affected members of one family with a c.1341G $>$ A; p.(Trp447Ter) variant in exon 6 all presented with additional signs of myopathy and distal arthropathy. ${ }^{8}$

\subsection{Analytical methods}

Gene sequencing provides the most common technical approach for detection of sequence variants. MLPA (multiplex ligation-dependent probe amplification) kits for detection of deletions/duplications of one or more exons of the FGD1 gene are commercially available. Sequence variants have also been detected using a whole-exome sequencing approach, in the past, ${ }^{12}$ and next-generation sequencing technologies are expected to rapidly accelerate the detection of causal variants in this condition in the future.

\subsection{Analytical validation}

This is undertaken by analysis of independent control samples for the presumed pathogenic variant found in affected individuals, comparison to database entries and published data, and testing of other affected/ unaffected relatives in the family to see if the variant segregates with the disease. These approaches will facilitate the distinction of pathogenic variants from polymorphisms, especially in the cases of missense variants

1.8 Estimated frequency of the disease (incidence at birth ('birth prevalence') or population prevalence)

Only 35 molecularly proven cases have been published worldwide. ${ }^{2-15}$ The majority of patients with a clinical diagnosis where details were published before the advent of molecular testing have not undergone subsequent molecular testing. Experience in Leuven (Prof. JP Fryns: personal communication), a typical-sized clinical genetics unit, suggests that two to three new patients with a proven variant in the FGD1 gene will be identified per year, a similar number as for Angelman and Prader-Willi syndrome. This gives an estimated population prevalence of AAS, which is equal to or slightly lower than to $1 / 25000$.

\footnotetext{
${ }^{1}$ Medicina Molecolare, Azienda Ospedaliera Universitaria Senese, Siena, Italy; ${ }^{2}$ Genetica Medica, USL9, Ospedale 'Misericordia', Grosseto, Italy; ${ }^{3}$ Manchester Academic Health Sciences Centre, St Mary's Hospital, Manchester, UK; ${ }^{4}$ Center for Human Genetics, University Hospital Leuven, Leuven, Belgium

*Correspondence: Dr A Orrico, Molecular Medicine, Azienda Ospedaliera Universitaria Senese, Policlinico 'S. Maria alle Scotte', Viale Bracci 2, 53100 Siena, Italy. Tel/Fax: +39 577 586264; E-mail: a.orrico@ao-siena.toscana.it
}

Received 30 April 2014; revised 1 August 2014; accepted 6 August 2014 
1.9 If applicable, prevalence in different ethnic groups:

Not applicable. The majority of individuals and families who have been studied molecularly to date are all of Caucasian extract (USA and Europe).

\subsection{Diagnostic setting}

\begin{tabular}{lll}
\hline & Yes & No \\
A. (Differential) diagnostics & $\bigotimes$ & $\square$ \\
B. Predictive testing & $\square$ & $\square$ \\
C. Risk assessment in relatives & $\bigotimes$ & $\square$ \\
D. Prenatal & $\bigotimes$ & $\square$
\end{tabular}

\section{Comment:}

This is not applicable as the signs of AAS are usually present in childhood and genetic testing, even in young children, is considered diagnostic and not predictive. Prenatal testing - see further (3.4) for considerations regarding prenatal diagnosis.

\section{TEST CHARACTERISTICS}

\begin{tabular}{|c|c|c|c|c|}
\hline & \multicolumn{2}{|c|}{ Genotype or disease } & \multirow{2}{*}{$\begin{array}{l}\text { A: True positives } \\
\text { B: False positives }\end{array}$} & \multirow{2}{*}{$\begin{array}{l}\text { C: False negative } \\
\text { D: True negative }\end{array}$} \\
\hline & Present & Absent & & \\
\hline \multicolumn{5}{|l|}{ Test } \\
\hline \multirow[t]{2}{*}{ Positive } & $A$ & B & Sensitivity: & $A /(A+C)$ \\
\hline & & & Specificity: & $D /(D+B)$ \\
\hline \multirow[t]{2}{*}{ Negative } & C & $\mathrm{D}$ & Positive predictive value: & $A /(A+B)$ \\
\hline & & & Negative predictive value: & $\mathrm{D} /(\mathrm{C}+\mathrm{D})$ \\
\hline
\end{tabular}

\subsection{Analytical sensitivity \\ (proportion of positive tests if the genotype is present) $100 \%$.}

\subsection{Analytical specificity}

(proportion of negative tests if the genotype is not present) $100 \%$.

\subsection{Clinical sensitivity}

(proportion of positive tests if the disease is present)

Approximately 22\%. ${ }^{1}$ To estimate the highest variant detection rate, only affected individuals who fully meet the classical diagnostic criteria for AAS should be taken into account. ${ }^{1}$ Testing only this group will, however, limit the probability of detecting pathogenic variants in less typical patients, who may represent broader clinical subtypes of AAS. It is already acknowledged that some patients with pathogenic variants do not have all the typical clinical features. ${ }^{13-15}$

The clinical sensitivity depends on variable factors such as age or family history. In reporting cases, a general statement to this effect should be given, even if a quantification can only be made case by case. Failure to detect a likely pathogenic variant in most patients referred for FGD1 analysis is likely to be largely attributable to the clinical and genetic heterogeneity of AAS and the fact that the clinical features overlap with those of several other disorders. Noonan syndrome in particular shows significant clinical overlap with short stature, hypertelorism, genital anomalies and ptosis. Other differential diagnoses include SHORT syndrome, pseudohypoparathyroidism and Robinow syndrome.
Especially the latter condition presents with many clinical similarities (short stature, hypertelorism, facial features). However, these individuals never have a 'shawl scrotum', while a mesomelic limb shortening represents a main typical feature of Robinow syndrome not described in the AAS.

Most of the disorders with overlapping features with AAS (hypertelorism, short stature, brachydactyly, male genital abnormalities) may be differentiated on clinical basis and addressed to specific genetic testing. However, as differences may not always be obvious, a possible targeted NGS approach in similar cases might be indicated and, in addiction to FGD1, should also include ROR2 and WNT5A, genes known to be involved in the pathogenesis of the Robinow syndrome. ${ }^{16,17}$

\subsection{Clinical specificity}

(proportion of negative tests if the disease is not present)

The clinical specificity can be dependent on variable factors such as age or family history. When reporting, a general statement should be given, even if a quantification can only be made case by case.

$100 \%$.

2.5 Positive clinical predictive value (life-time risk of developing the disease if the test is positive)

Not applicable: see comment to the point 1.10 ' $\mathrm{D}$ ' about predictive tests.

2.6 Negative clinical predictive value (probability of not developing the disease if the test is negative)

Assume an increased risk based on family history for a non-affected person. Allelic and locus heterogeneity may need to be considered in individuals who test negative.

Index case in that family had been tested:

Not applicable (due to genetic heterogeneity).

Index case in that family had not been tested:

Not applicable.

\section{CLINICAL UTILITY}

3.1 (Differential) diagnostics: The tested person is clinically affected (To be answered if in 1.10 'A' was marked)

\subsubsection{Can a diagnosis be made other than through a genetic test?}

\begin{tabular}{|c|c|c|}
\hline No & $\otimes$ (continue with 3.1 .4 ) & \\
\hline \multirow[t]{7}{*}{ Yes } & $\square$ & \\
\hline & Clinically & $\square$ \\
\hline & Imaging & $\square$ \\
\hline & Endoscopy & $\square$ \\
\hline & Biochemistry & $\square$ \\
\hline & Electrophysiology & $\square$ \\
\hline & Other (please describe) & \\
\hline
\end{tabular}

3.1.2 Describe the burden of alternative diagnostic methods to the patient.

Not applicable.

3.1.3 How is the cost effectiveness of alternative diagnostic methods to be judged?

Not applicable. 
3.1.4 Will disease management be influenced by the result of a genetic test?

No $\square$
Yes $\otimes$

Therapy (please There are no specific therapies for AAS. Some features describe) (hypospadias, inguinal or umbilical hernias, cryptorchidism and unusually severe craniofacial features) may need surgical intervention..$^{15}$ Radiological assessment of the cervical spine should be carried out, with orthopaedic referral if necessary, as compression of cervical nerve roots may be the consequence of cervical vertebral defects (hypoplasia of the first cervical vertebra, unfused posterior arch, synostosis, anomaly of the odontoid). ${ }^{18}$ The effect of growth hormone (GH) treatment on height gain has been reported only in preliminary studies and needs confirmation. ${ }^{19}$ In the case of neurodevelopmental symptoms, generally mild intellectual disability and attention deficit and hyperactivity disorder (ADHD), a neuropsychiatric opinion and input may be useful.20,21

Prognosis (please Due to the clinical and genetic heterogeneity, the describe) identification of an FGD1 variant in an AAS patient will not lead to an altered prognosis, when compared with patients in whom a variant was not found. However, the molecular test is essential to confirm clinical diagnosis and for accurate genetic counselling of the families concerned.

Management (please Multidisciplinary clinical follow-up (paediatrics, orthodescribe) paedic, neuropsychiatric, child development team). A positive genetic test will impact on genetic counselling by permitting carrier detection, diagnosis in individuals with milder manifestations and the provision of an accurate recurrence risk for the families concerned.

3.2 Predictive Setting: The tested person is clinically unaffected but carries an increased risk based on family history

(To be answered if in 1.10 ' $\mathrm{B}$ ' was marked)

3.2.1 Will the result of a genetic test influence lifestyle and prevention?. If the test result is positive (please describe):

Not applicable.

If the test result is negative (please describe):

Not applicable.

3.2.2 Which options in view of lifestyle and prevention does a person at-risk have if no genetic test has been done (please describe)? Not applicable.

3.3 Genetic risk assessment in family members of a diseased person (To be answered if in 1.10 ' $\mathrm{C}$ ' was marked)

3.3.1 Does the result of a genetic test resolve the genetic situation in that family?. A positive test (finding of a FGD1 variant) will confirm the diagnosis of AAS and facilitate accurate genetic counselling. It is useful in particular for carrier detection in females who may not manifest significant clinical signs and for extended family members. The assessment of recurrence risk for future pregnancies will be possible. A negative test will not completely rule out the possibility of AAS.

3.3.2 Can a genetic test in the index patient save genetic or other tests in family members? Yes.
3.3.3 Does a positive genetic test result in the index patient enable a predictive test in a family member?. Not applicable: see comment to the point 1.10 ' $\mathrm{B}$ '.

\subsection{Prenatal diagnosis}

(To be answered if in 1.10 'D' was marked).

3.4.1 Does a positive genetic test result in the index patient enable a prenatal diagnosis? Prenatal diagnosis for pregnancies at increased risk is possible when the disease-causing variant in the family has been identified. However, in practice, prenatal testing is unlikely to be requested frequently as even in male patients physical signs can be mild and the broad variability of clinical expression in an individual family makes prediction of the phenotype difficult. ${ }^{22}$

\section{IF APPLICABLE, FURTHER CONSEQUENCES OF TESTING}

Please assume that the result of a genetic test has no immediate medical consequences. Is there any evidence that a genetic test is nevertheless useful for the patient or his/her relatives? (Please describe)

The result of an FGD1 genetic test may have no immediate medical consequences for the affected individual and their family, but having a positive molecular genetic diagnosis will influence genetic counselling and may influence reproductive decisions. It is likely that relatives will consider genetic counselling and carrier testing to assess their own risks. In many cases a positive FGD1 test has removed the need for further diagnostic investigations.

\section{CONFLICT OF INTEREST}

The authors declare no conflict of interest.

\section{ACKNOWLEDGEMENTS}

This work was supported by EuroGentest, an EU-FP6-supported NoE, contract number 512148 (EuroGentest Unit 3: 'Clinical genetics, community genetics and public health', Workpackage 3.2). JCS is supported by the Manchester Centre for Genomic Medicine within the Central Manchester NHS Foundation Trust.

1 Pasteris NG, Buckler J, Cadle AB, Gorski JL: Genomic organization of the faciogenital dysplasia (FGD1; Aarskog syndrome) gene. Genomics 1997; 43: 390-394.

2 Orrico A, Galli L, Faivre L et al: Aarskog-Scott Syndrome: clinical update and report of nine novel variants of the FGD1 gene. Am J Med Genet A 2010; 152A: 313-318.

3 Schwartz CE, Gillessen-Kaesbach G, May M et al: Two novel variants confirm FDG1 is responsible for the Aarskog syndrome. Eur J Hum Genet 2000; 8: 869-874.

4 Bedoyan JK, Friez MJ, Dupont B, Ahmad A: First case of deletion of the faciogenital dysplasia 1 (FGD1) gene in a patient with Aarskog-Scott Syndrome. Eur J Med Genet 2009; 52: 262-264.

5 Baldi M, Mura I, De Cassan P et al: Sindrome di Aarskog: nuove mutazioni del gene FGD1. XII Congresso SIGU, Abstract book: poster 105, Torino, 2009.

6 Pilozzi-Edmonds L1, Maher TA, Basran RK et al: Fraternal twins with Aarskog-Scott Syndrome due to maternal germline mosaicism. Am J Med Genet A 2011; 155A: 1987-1990.

7 Verhoeven WM, Egger JI, Hoogeboom AJ: X-linked Aarskog syndrome: report on a novel FGD1 gene variant. Executive dysfunction as part of the behavioural phenotype. Genet Couns 2012; 23: 157-167.

8 Al-Semari A, Wakil SM, Al-Muhaizea MA et al: Novel FGD1 variant underlying Aarskog-Scott Syndrome with myopathy and distal arthropathy. Clin Dysmorphol 2013; 22: 13-17.

9 Altıncık A, Kaname T, Demir K, Böber E: A novel variant in a mother and a son with Aarskog-Scott Syndrome. J Pediatr Endocrinol Metab 2013; 26: 385-388.

10 Orrico A, Galli L, Cavaliere ML et al: Phenotypic and molecular characterisation of the Aarskog syndrome: a survey of the clinical variability in light of $F D G 1$ variant analysis in 46 patients. Eur J Hum Genet 2004; 12: 16-23.

11 Ronce N, Maystadt I, Hubert C et al: Aarskog-Scott Syndrome: first report of a duplication in the FGD1 gene. Clin Genet 2012; 82: 93-96.

12 Aten E, Sun Y, Almomani R et al: Exome sequencing identifies a branch point variant in Aarskog-Scott Syndrome. Hum Mutat 2013; 34: 430-434. 
13 Lebel RR, May M, Pouls S, Lubs HA, Stevenson RE, Schwartz CE: Non-syndromic X-linked mental retardation associated with a missense variant (P312L) in the FGD1 gene. Clin Genet 2002; 61: 139-145.

14 Bottani A, Orrico A, Galli L et al: Unilateral focal polymicrogyria in a patient with classical Aarskog-Scott Syndrome due to a novel missense variant in an evolutionary conserved RhoGEF domain of the faciogenital dysplasia gene FGD1. Am J Med Genet $A$ 2007; 143A: 2334-2338.

15 Orrico A, Galli L, Obregón MG, de Castro Perez MF, Falciani M, Sorrentino V: Unusually severe expression of craniofacial features in Aarskog-Scott Síndrome due to a nove truncating variant of the FDG1 gene. Am J Med Genet A 2007; 143: 58-63.

16 van Bokhoven $\mathrm{H}$, Celli $\mathrm{J}$, Kayserili $\mathrm{H}$ et al: Mutation of the gene encoding the ROR2 tyrosine kinase causes autosomal recessive Robinow syndrome. Nat Genet 2000; 25: 423-426.

17 Person AD, Beiraghi S, Sieben CM et al: WNT5A mutations in patients with autosomal dominant Robinow syndrome. Dev Dyn 2010; 239: 327-337.
18 Fryns JP: Aarskog syndrome: the changing phenotype with age. Am J Med Genet 1992; 43: 420-427.

19 Satoh M, Yokoya S: Anabolic steroid and gonadotropin releasing hormone analog combined treatment increased pubertal height gain and adult height in two children who entered puberty with short stature. J Pediatr Endocrinol Metab 2006; 19 1125-1131.

20 Orrico A, Galli L, Buoni S et al: Attention-deficit/hyperactivity disorder (ADHD) and variable clinical expression of Aarskog-Scott Syndrome due to a novel FGD1 gene variant (R408Q). Am J Med Genet A 2005; 135: 99-102.

21 Kaname T, Yanagi K, Okamoto N, Naritomi K: Neurobehavioral disorders in patients with Aarskog-Scott Syndrome affected by novel FGD1 variants. Am J Med Genet $A$ 2006; 140: 1331-1332.

22 Shalev SA, Chervinski E, Weiner E, Mazor G, Friez MJ, Schwartz CE: Clinical variation of Aarskog syndrome in a large family with 2189 delA in the FGD1 gene. Am J Med Genet A 2006; 140: 162-165. 